\title{
Thermal Analysis of Overload Protection Relays using Finite Element Method
}

\author{
Adrian T. Plesca* \\ Department of Power Engineering, Gheorghe Asachi Technical \\ University of lasi, Romania; matrix_total2000@yahoo.com
}

\begin{abstract}
This paper describes a three-dimensional thermal model of the bimetal releaser from low voltage power circuit breakers. The model can be used to analyse the thermal behaviour of the bimetal strip during both steady-state and transient conditions. The steady-state thermal simulations have been done. The maximum temperature is obtained at the extreme of the movable end terminal of the bimetallic strip. The steady-state conditions are reached after approximate 600 seconds from the initial moment of warming. A similar time evolution can be noticed for trip and force characteristics. To validate the three-dimensional thermal model, some experimental tests both in steady-state and transient conditions have been done. It has been recorded the time evolution of the temperature rises, cooling, trip and force characteristics during transient conditions. There is a good correlation between experimental and simulation results. Hence, the maximum difference between the experimental and simulation values is less than $2.5^{\circ} \mathrm{C}$.
\end{abstract}

Keywords: Thermal Analysis, Bimetallic Strip, Finite Element Method.

\section{Introduction}

In the case of electric motors or power transformers which operate at a certain rated power, it appears power loss because of electric phenomena (power loss of ferromagnetic circuits and windings) and mechanical phenomena (ball bearings and sliding electric contacts with mechanical friction). These power losses lead to external heat which depends on the rated power of the motors or power transformers. A part of this power loss is transmitted to the environment and another part is absorbed by the motor or transformer which warms up some components from the electric machines, especially the windings.

These heating means important thermal wear which may lead to:

- weakening insulation (the decreasing of the insulation features from the electric machines);
- aging sheets (the decreasing of the magnetic features of the ferromagnetic circuits which lead to increase of the power loss and therefore, more heat).

In the case of power distribution lines which supply electric motors or different type of loads; there are also power losses which transform into heat. To avoid aging insulation of cables and conductors, on each section of the power distribution lines, a certain current density, actually, a certain rated current is recommended.

The current increasing may be due to an overload or failure in the power system. The protection devices dedicated to clear different types of overloads include the bimetallic strip. This is the main component part from circuit breakers. Hence, in a thermal-magnetic circuit breaker, the trip unit includes elements designed to sense the heat resulting from an overload condition and the high current resulting from a short circuit.

*Corresponding author:

Adrian T. Plesca (matrix_total2000@yahoo.com) 
Thermal-magnetic circuit breakers employ a bimetallic strip to sense overload conditions. When sufficient over current flows through the circuit breaker's current path, heat builds up causes the bimetallic strip to bend. After bending a predetermined distance, the bimetallic strip makes contact with the tripper bar activating the trip mechanism.

A bimetallic strip is made of two dissimilar metals bonded together. The two metals have different thermal expansion characteristics, so the bimetallic strip bends when heated. As current rises, heat also rises. The hotter the bimetallic becomes, the more it bends. After the source of heat is removed, as when the circuit breaker contacts open, the bimetallic strip cools and returns to its original condition. This allows a circuit breaker to be normally reset once the overload condition has been corrected.

The warm up of the bimetallic strip can be done with or without the electric current. In the situation of using the electric current to warm up the bimetallic strip, there are three methods to provide the operating of the thermal relay:

- direct electric heating (it uses the heat because of Joule effect, when the electric current flows through the bimetallic strip. This method allows a direct and simultaneously heating in the whole cross-section of the bimetallic strip, which means a real advantage to use this heating method);

- indirect electric heating (it uses at low values of the electric current. The bimetallic strip has heat windings made by materials with high electric resistivity. Between the bimetallic strip and the heat winding there is an electric insulated layer with good thermal stress);

- mixed electric heating (it uses also at low values of the electric current. This method is a combination between thermal effect because of direct electric current which flows through the bimetallic strip and a winding with high resistivity).

There is a tendency to replace the traditional thermal relays with electronic relays which have as core component a microprocessor or a microcontroller, [1-4].

To utilize the motor most effectively under distorted supply condition, a proper derating of the motor is required which essentially depends on an accurate determination of the motor winding temperature, [5-7]. The development of a novel overload and short circuit protection relay for three phase induction motors without requiring motor current as its input parameter is presented in [8]. The axial leakage flux of the motor is used instead as the sensing parameter. In previous works, [9-11], special attention was paid to achieve models of the induction motors, in order to identify key parameters and the interactions between electrical, thermal and mechanical specific parameters of the electric motor. The models are very useful to design protection devices which include also the thermal image of the motors, [12-15].

A third-order thermal model capable of giving good temperature rise predictions for any arbitrary variable-load, variable-speed, operating cycle, is presented in [16]. A new thermal model is proposed that not only protects the motor from overload under normal power supply condition, but also applies a proper derating factor under waveform distortion, is described in [17]. The temperature distribution of a thermal overload relay obtained by using finite element analysis taking into account the current distribution in current-carrying conductors is presented in $[18,19]$. A detailed analysis of the trajectories of the voltage and current space vectors in the synchronously rotating $\mathrm{d}$-q reference frame is presented in [20]. Based on this analysis, a robust and efficient rotor temperature estimator is proposed. In [21], standard loss of insulation life equations have been applied to step up transformers as part of the design of an intelligent relay that would calculate the time left before a possible trip (assuming that conditions remained constant) and should allow the operators to avoid tripping the transformer. Revised transformer overload ratings as well as predictive protection can be obtained with an accurate thermal model of the limiting hottest spot temperatures, $[22,23]$. The work presented in [24] explains the ambiguity introduced in the standard and addresses thermal protection from the perspective of a thermal model that provides optimum protection.

This paper deals with a three-dimensional thermal simulation of a bimetallic strip which is the key-component from a thermal releaser of low voltage circuit breakers. The simulation results have been compared with the experimental ones.

\section{Thermal Model and Simulations}

The balance equation of heat transfer for the bimetallic strip of the thermal releaser has the following general expression,

$$
\begin{aligned}
& \frac{\gamma_{c}}{\lambda} \frac{\partial \vartheta}{\partial t}=\frac{\partial^{2} \vartheta}{\partial x^{2}}+\frac{\partial^{2} \vartheta}{\partial y^{2}}+\frac{\partial^{2} \vartheta}{\partial z^{2}}+ \\
& \left(\frac{\rho_{0} \alpha I^{2}}{\lambda S(x, y, z)^{2}}-\frac{l_{p}(x, y, z) k}{\lambda S(x, y, z)}\right) \vartheta+\frac{\rho_{0} I^{2}}{\lambda S(x, y, z)^{2}}
\end{aligned}
$$


where:

$\rho$ - electrical resistivity;
$\gamma$ - material density;
$c$ - specific heat;
$\lambda$ - thermal conductivity;
$\vartheta$ - temperature rise;
$\alpha$ - coefficient of electrical resistivity variation with temperature;

$k$ - convection coefficient;

$S$ - cross-section of the bimetallic strip;

$l_{p}$ - perimeter length of the cross-section.

The above expression is complex, and it demands a numerical procedure to evaluate the temperature distribution both in steady-state or transient conditions. It is desirable to restate the problem by considering various forms of discretization. The discretised form of the problem only requires the solution to be satisfied at a finite number of points in the region; and in the remainder of the region, appropriate interpolations may be used. Thus, this case is reduced to a purely algebraic form involving only the basic arithmetic operations, which could in turn be solved by numerical methods.

The progress in computer technology enables the modelling and simulation of more and more complex structures in less time, thus, the cost-effectiveness of numerical procedures has been greatly enhanced. These methods have become very accurate and reliable for solving initial and boundary value problems. One common numerical technique in thermal analysis is the finite element method. The basic idea of this method is to discretise the domain $\mathrm{V}$, into several sub domains, or finite elements. These elements can be irregular and possess different properties so that they form a basis to discretise complex structures, or structures with mixed material properties. More, they can accurately model the domain boundary regardless of its shape.

Using Galerkin method and including convection boundary condition, the discretized equations for the heat transfer are as follows:

$$
\begin{aligned}
& \int_{V} \gamma c \frac{\partial \theta}{\partial t} N_{i} d V+\int_{V}\left[\frac{\partial N_{i}}{\partial x} \frac{\partial N_{i}}{\partial y} \frac{\partial N_{i}}{\partial z}\right] \lambda[B]\{\theta\} d V \\
& =\int_{V} \rho j^{2} N_{i} d V-\int_{S} k\left(\theta-\theta_{a}\right) N_{i} d S
\end{aligned}
$$

where $[\mathrm{N}]$ is the matrix of shape functions and [B] is the matrix for temperature gradients interpolation. Shape functions $N_{i}$ are used for interpolation of temperature and temperature gradients inside a finite element:

$$
\begin{aligned}
& \theta=[N]\{\theta\}, \quad[N]=\left[N_{1} N_{2} N_{3} \ldots\right], \quad\{\theta\}=\left\{\theta_{1} \theta_{2} \theta_{3} \ldots\right\} \\
& \left\{\begin{array}{l}
\frac{\partial \theta}{\partial x} \\
\frac{\partial \theta}{\partial y} \\
\frac{\partial \theta}{\partial z}
\end{array}\right\}=\left[\begin{array}{lll}
\frac{\partial N_{1}}{\partial x} & \frac{\partial N_{2}}{\partial x} & \frac{\partial N_{3}}{\partial x} \ldots \\
\frac{\partial N_{1}}{\partial y} & \frac{\partial N_{2}}{\partial y} & \frac{\partial N_{3}}{\partial y} \ldots \\
\frac{\partial N_{1}}{\partial z} & \frac{\partial N_{2}}{\partial z} & \frac{\partial N_{3}}{\partial z} \ldots
\end{array}\right]\{\theta\}=[B]\{\theta\}
\end{aligned}
$$

The finite element equations corresponding to the heat transfer have the following matrix form:

$$
\begin{aligned}
& {[A]\{\dot{\theta}\}+\left(\left[L_{c}\right]+\left[L_{k}\right]\right)\{\theta\}=\left\{R_{Q}\right\}+\left\{R_{k}\right\}} \\
& {[A]=\int_{V}[N]^{T} \gamma c[N] d V ; \quad\left[L_{c}\right]=\int_{V}[B]^{T} \lambda[B] d V ;} \\
& {\left[L_{k}\right]=\int_{S}[N]^{T} k[N] d S} \\
& {\left[R_{Q}\right]=\int_{V} \rho j^{2}[N]^{T} d V ; \quad\left[R_{k}\right]=\int_{S} k \theta_{a}[N]^{T} d S}
\end{aligned}
$$

A 3D model for the bimetallic strip from an over current thermal releaser has been developed using a specific software, the Pro-ENGINEER, an integrated thermal design tool for all type of accurate thermal analysis on devices. The 3D thermal model had taken into consideration the real shape of the bimetallic strip, as shown in Figure 1.

A typical application is when this type of bimetallic strip is used to protect against over loads a low voltage power distribution system. The current which flows through the thermal releaser has been considered about 15A. At this current value, some experimental tests have been done in order to estimate the power losses, actually the heat load to be applied on the bimetallic strip. Therefore, after measurements and calculations, the following power loss value has been obtained: $7.5 \mathrm{~W}$.

For all thermal simulations 3D finite elements ProMECHANICA software has been used. The heat load has been applied on the main component of the thermal releaser, the bimetallic strip. There is a uniform spatial

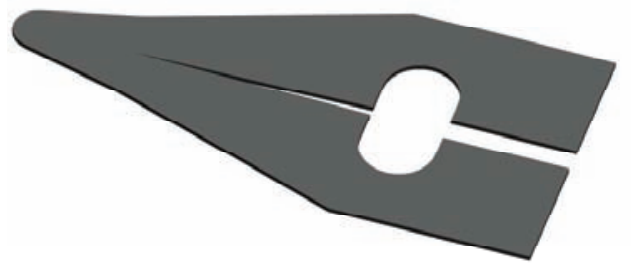

Figure 1. Thermal model of the bimetallic strip. 


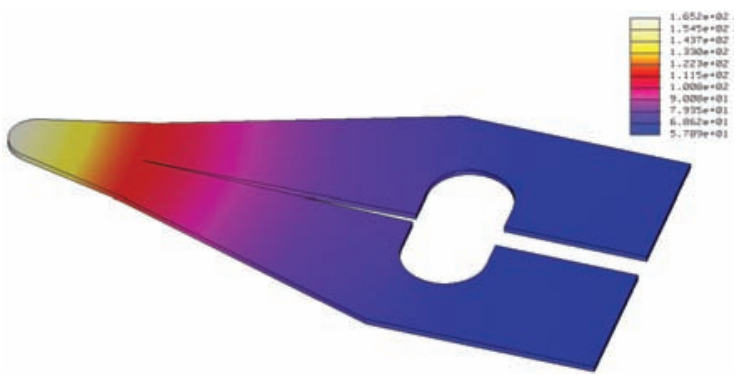

Figure 2. Temperature distribution of the bimetallic strip.

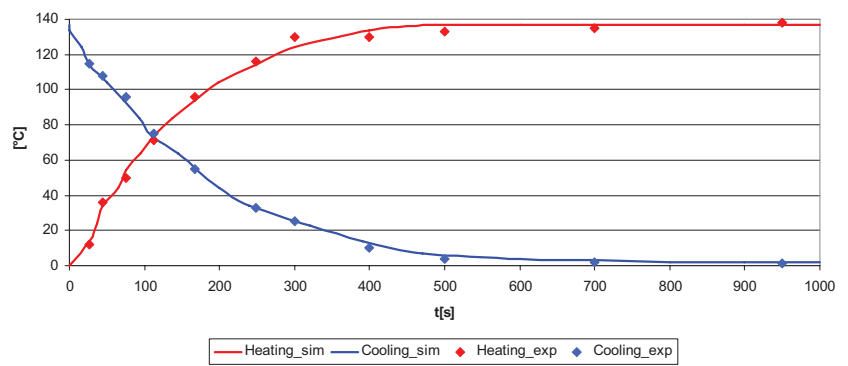

Figure 3. Time evolution of the heating and cooling characteristics of the bimetallic strip under the current value of 15A. Comparison between simulation results (Heating sim, Cooling_sim) and experimental values (Heating_exp, Cooling_exp).

distribution on this component. The mesh of this $3 \mathrm{D}$ bimetallic strip thermal model has been done using tetrahedron solids element types with the following allowable angle limits (degrees): maximum edge: 175; minimum edge: 5; maximum face: 175 ; minimum face: 5 . The maximum aspect ratio was 30 and the maximum edge turn (degrees): 95. Also, the geometry tolerance had the following values: minimum edge length: 0.0001; minimum surface dimension: 0.0001; minimum cusp angle: 0.86; merge tolerance: 0.0001 . The single pass adaptive convergence method to solve the thermal steady-state simulation has been used. The ambient temperature was about $26^{\circ} \mathrm{C}$. From experimental tests, it was computed the convection coefficient $\mathrm{k}=$ $16.5 \mathrm{~W} / \mathrm{m}^{2 \circ} \mathrm{C}$, for this type of bimetallic strip. Hence, it was considered the convection condition like boundary condition for the outer boundaries and it has been applied on surfaces with a uniform spatial variation and a bulk temperature of $26^{\circ} \mathrm{C}$

Further on, some steady state thermal simulations have been done. The temperature distribution on the bimetallic strip is shown in Figure 2.

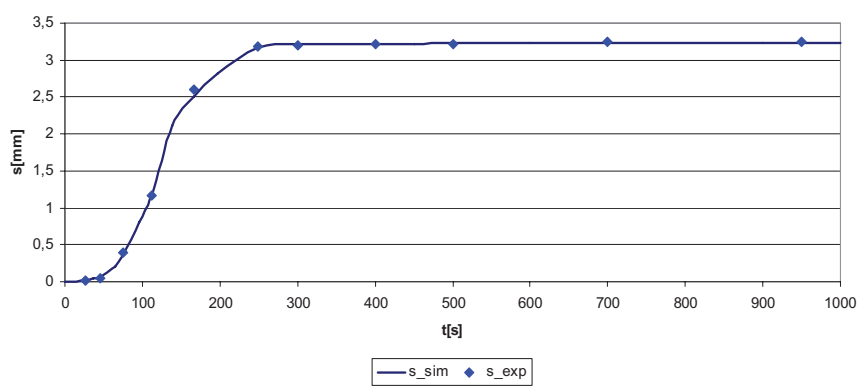

Figure 4. Time evolution of the trip characteristic of the bimetallic strip under the current value of $15 \mathrm{~A}$. Comparison between simulation results (s_sim) and experimental values (s_exp).

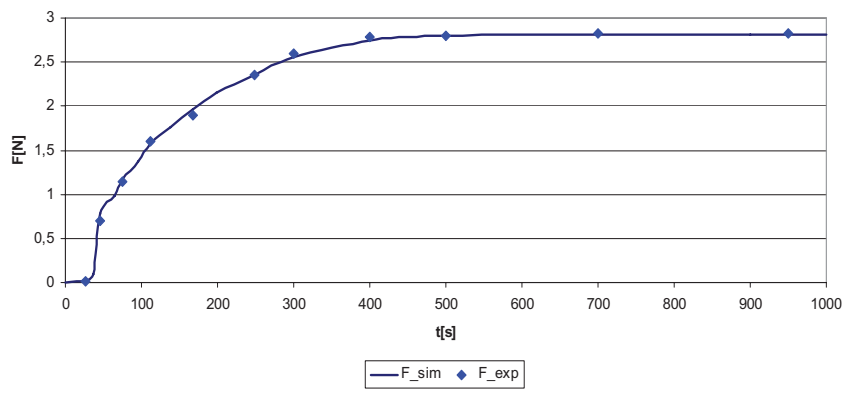

Figure 5. Time evolution of the force characteristic of the bimetallic strip under the current value of 15A. Comparison between simulation results (F_sim) and experimental values (F_exp).

In order to analyse the time evolution of the temperature for the bimetallic strip, a series of transient thermal simulations have been done. The temperature rise time evolution and the cooling of the bimetallic strip till to the ambient temperature are presented in the graphics from Figure 3.

Also, the trip and the force of the movable end terminal of the bimetallic strip have been simulated during transient conditions when the thermal releaser is getting warm. The results are presented in the graphics from Figures 4 and 5.

As can be seen in the $3 \mathrm{D}$ thermal simulation picture from Figure 2, the maximum temperature $\left(165.2^{\circ} \mathrm{C}\right)$ is obtained at the extreme of the movable end terminal of the bimetallic strip. This is explained because in that area the cross-section of the bimetallic strip is minimum, hence at the same testing current of $15 \mathrm{~A}$, the current density has the maximum value in that area. From the graphics presented in Figure 3, it can be observed that the steady-state conditions are reached after approximate 600 


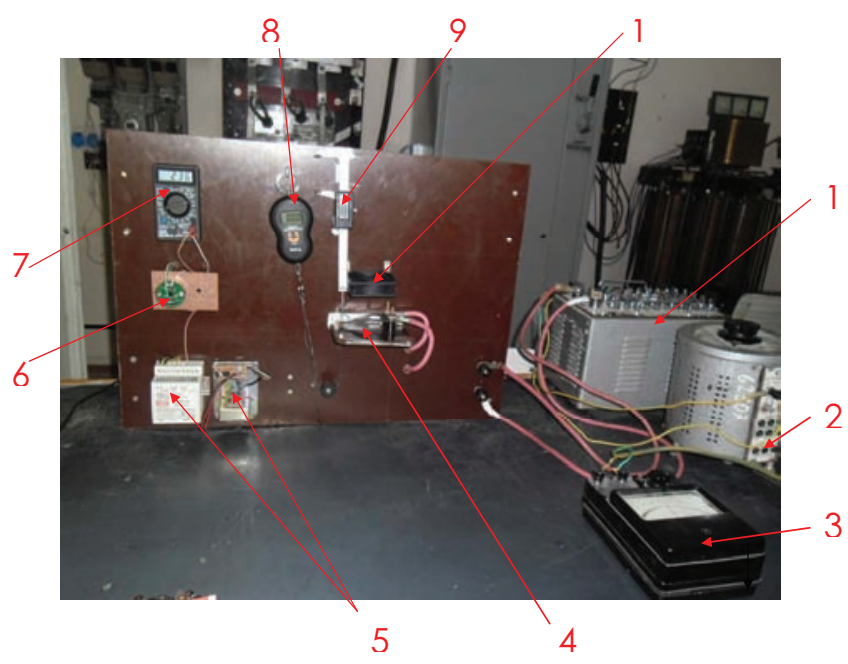

Figure 6. Experimental set-up with the following main components: 1 - power current source; 2 - autotransformer; 3 - ammeter; 4 - bimetal strip; 5 - voltage sources; 6 - amplifier; 7 - digital multimeter; 8 - digital weighing; 9 - digital dynamometer; 10 - fan.

seconds from the initial moment of warming or cooling conditions back to the environment temperature. Hence, the time constant of this type of thermal releaser is about 150 seconds. A similar time evolution as during heating case can be noticed for trip and force characteristics, Figures 4 and 5. The maximum values, when the bimetallic strip is crossed by $15 \mathrm{~A}$, are $3.23 \mathrm{~mm}$ for the trip and $2.81 \mathrm{~N}$ in the case of force at the movable end terminal of the bimetallic strip.

\section{Experimental Tests}

To validate the thermal model some experimental tests have been made in the same conditions as in the case of thermal simulations. The experimental set-up is shown in Figure 6.

The auto-transformer 2, adjusts the input voltage for the high current supply device 1 . This has an adjustable primary voltage and on the secondary side, high value current can be obtained. The current value is measured by an ammeter 3. Using a proper thermocouple type $\mathrm{K}$, the temperature on the movable end terminal of the bimetallic strip 4, has been acquired. The small voltage signals provided by thermocouple, have been amplified using a signal conditioning board 6, type AT2F-16 with the error of $\pm 0.5 \%$. The amplified signal was the input for a digital multimeter 7 . In order to obtain a forced cooling for

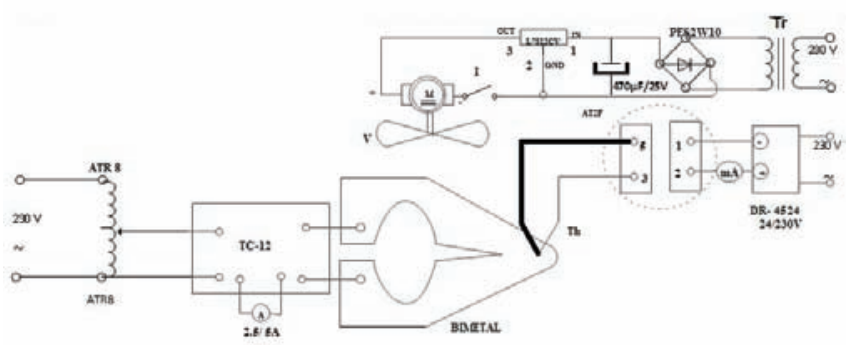

Figure 7. Electric circuit of the experimental set-up.

the bimetallic strip, a fan 10 has been mounted. Both the signal conditioning board and the fan are supplied from the voltage sources 5 , which provides $24 \mathrm{Vdc}$ and respectively, $12 \mathrm{Vdc}$. The force of the movable end terminal of the bimetallic strip is measured using a digital weighing 8 , and the trip can be measured with a digital dynamometer 9. An electric circuit diagram used for experimental tests is shown in Figure 7.

On the other hand, the differences between the temperature values resulting from experimental tests and those obtained during simulations are due to various factors: measurement errors, thermal model simplifications and mounting test conditions. Nevertheless, the maximum difference between the experimental and simulation results is less than $2.5^{\circ} \mathrm{C}$.

\section{Conclusions}

To understand and to optimize the operating mechanisms of power electrical equipment, the thermal behaviour of the bimetallic releaser is of great interest. The obtained 3D thermal model allows analysis of the thermal behaviour of bimetallic strip from power circuit breakers during both steady-state or transient conditions. The thermal model provides the temperature distribution in steady-state conditions, heating/cooling, trip and force characteristics of the thermal releaser under transient operating conditions.

The three-dimensional thermal model of the bimetallic strip could be used as a tool for different types of thermal relays and low voltage power circuit breaker designing. Some experimental tests have been made with the aim to validate the proposed 3D thermal model. The maximum difference between the experimental and simulation results is less than $2.5^{\circ} \mathrm{C}$. Using the proposed $3 \mathrm{D}$ thermal model the over current relays and circuit breaker designing can be improved and there is the possibility to obtain new solutions 
for a better correlation between protection characteristics of the different types of power electrical equipment.

\section{Acknowledgements}

This work was supported by CNCSIS - UEFISCDI, project number 610 PNII - CAPACITATI, 2013.

\section{References}

1. Schweitzer E O, and Zocholl S E (1996). The universal overcurrent relay, IEEE Industry Applications Magazine, vol 2(3), 28-34.

2. Pinjia Z, Yi, D. et al. (2009). A transfer-function-based thermal model reduction study for induction machine thermal overload protective relays, IEEE Transactions on Industry Applications, vol 46, 1919-1926.

3. Cantemir L, Nituca C et al. (2011). Unconventional current collection from a contact line for electric traction vehicles, International Conference on Pantograph Catenary Interaction Framework for Intelligent Control, Amiens, France.

4. Nițucă C (2013). Thermal analysis of electrical contacts from pantograph-catenary system for power supply of electric vehicles, Electric Power Systems Research, vol 96, 211-217.

5. Khederzadeh M (2006). Thermal overload protection of induction motors under waveform distortion, Proceedings of the 41st International Universities Power Engineering Conference, vol 3, 866-870.

6. Fox G (1990). Overload protection for medium voltage motors controlled by switchgear starters, Record of Annual Pulp and Paper Industry Technical Conference, 82-86.

7. Vico J, Allcock D et al. (2011). Protection and control of low voltage motors used in industrial applications, IEEE Industrial and Commercial Power Systems Technical Conference, 1-8.

8. Mittra D K, Chatterjee T K et al. (2010). A new approach for overload cum short circuit protection of three phase induction motors using axial leakage flux, 10th IET International Conference on Developments in Power System Protection, $1-4$.

9. Zhi G, Colby R S et al. (2008). A model reduction perspective on thermal models for induction machine overload relays, IEEE Transactions on Industrial Electronics, vol 55(10), 3525-3534.

10. Abou-El-Ela M S, Megahed A I et al. (1996). Thermal model based digital relaying algorithm for induction motor protection, Canadian Conference on Electrical and Computer Engineering, vol 2, 1016-1019.
11. Zocholl S E (2006). Understanding service factor, thermal models, and overloads, 59th Annual Conference for Protective Relay Engineers.

12. Zocholl S E, Schweitzer E O, (1984). Thermal protection of induction motors enhanced by interactive electrical and thermal models, IEEE Power Engineering Review, vol : PER-4 (7), 48.

13. Whatley P, Lanier M et al. (2008). Enhanced motor protection with the slip-dependent thermal model: a case study, 61st Annual Conference for Protective Relay Engineers, 204-214.

14. Ransom D L and Hamilton R (2013). Extending motor life with updated thermal model overload protection, IEEE Transactions on Industry Applications, vol 99, 1.

15. Nituca C (2013). Thermal analysis for a double sided linear induction motor, European Scientific Journal, vol 9(9), 38-50.

16. Valenzuela M A, and Reyes P (2010). Simple and reliable model for the thermal protection of variable-speed selfventilated induction motor drives, IEEE Transactions on Industry Applications, vol 46(2), 770-778.

17. Khederzadeh M (2007). Enhanced thermal model for motors fed with distorted waveforms, IEEE Power Engineering Society General Meeting, 1-8.

18. Kawase Y, Ichihashi T et al. (1999). Heat analysis of thermal overload relays using 3-D finite element method, IEEE Transactions on Magnetics, vol 35(3), 1658-1661.

19. Chiriac G (2012). Thermal analysis of fuses with variable cross-section fuselinks, Electric Power Systems Research, vol 92, 73-80.

20. Zhi, G, and Habetler T G et al. (2005). A robust rotor temperature estimator for induction machines in the face of changing cooling conditions and unbalanced supply, IEEE International Conference on Electric Machines and Drives, 591-596.

21. Weekes T, Molinski T et al. (2004). Transient transformer overload ratings and protection, IEEE Electrical Insulation Magazine, vol 20(2), 32-35.

22. Swift G (2001). Adaptive Transformer thermal overload protection, IEEE Transactions on Power Delivery, vol 16(4), 516-521.

23. Carneiro J S A and Ferrarini L (2010). Preventing thermal overloads in transmission circuits via model predictive control, IEEE Transactions on Control Systems Technology, vol 18 (6), 1406-1412.

24. Zocholl S E and Benmouyal G (2005). On the protection of thermal processes, IEEE Transactions on Power Delivery, vol 20(2), 1240-1246. 